\title{
Comparison of Retropubic Colposuspension, TVT and TOT in Management of Stress Urinary Incontinence: A Tertiary Care Centre Experience
}

\author{
Authors \\ Vaibhav Vikas ${ }^{1}$, Shanky Singh ${ }^{2}$, Priyabrata Das ${ }^{3}$, Jatin Soni ${ }^{4}$ \\ ${ }^{1,2,3,4}$ Department of Urology, Government Medical College, Thiruvananthapuram, Kerala, India \\ Corresponding Author \\ Shanky Singh \\ Address- RNRA-27, Rajiv Gandhi Nagar, Medical College PO, Trivandrum-695011
}

Email: shankydt@gmail.com,contact-9497366747

\begin{abstract}
Background: Stress Urinary incontinence (SUI) is a condition that affects mainly females. Initially, SUI is managed conservatively and surgical approach is reserved for patients who fail conservative treatment. Surgery for SUI has evolved over years with inclination towards less invasive procedures. This is a retrospective study done at tertiary care centre in South India over a period of 3 years which compares long term outcomes of retropubic colposuspension, TVT and TOT surgeries for SUI.

Result- Total of 37 patients were operated by these three surgeries. Outcomes from all the three groups were comparable.
\end{abstract}

Keywords- Stress urinary incontinence, mid urethral slings, transobturator taping, tension free vaginal tape, Bursch colposuspension.

\section{INTRODUCTION}

Stress urinary incontinence (SUI) is best defined by the International Continence Society as "involuntary leakage of urine on exertion, effort, coughing, or sneezing ${ }^{[1]}$. SUI is a common health problem with major impact on Quality of Life (QOL); prevalence rate ranges from $12.8 \%$ to $46.0 \%{ }^{[1]}$. SUI is the most common type of urinary incontinence in premenopausal women (which is seen in almost $50 \%$ of patients $)^{[2]}$. $30 \%$ patients may have mixed incontinence. SUI may lead to restriction of physical and social activity, self-imposed social isolation ${ }^{[3,4]}$, and sexual dysfunction ${ }^{[5]}$. Initially, SUI should be managed conservatively including pelvic floor muscle training (PFMT), electrical stimulation or pharmacotherapy ${ }^{[6]}$. There is continuous evolvement of surgical techniques. All the surgical procedures aim to achieve less postoperative pain and shorter hospital stay with quicker recovery period ${ }^{[6]}$. Various surgical procedures include Transobturator taping (TOT), standard mid-urethral slings (SMUS), tension-free vaginal tapes (TVT) and colposuspension [7]-[10] This is a retrospective study about the surgeries for stress urinary incontinence carried out in last 2 years at a tertiary care centre in South India.

\section{MATERIAL AND METHODS}

Study design- Retrospective study (a case series)

Study period- 3 years 
Sample size- Total of 37 patients underwent surgeries for stress urinary incontinence at our institution from June 2013 to May 2016.

\section{Aim}

To compare the long term outcomes of Bursch colposuspension, TVT and TOT surgeries for female SUI.

\section{Inclusion Criteria}

1. All patients who underwent surgery for SUI.

2. All operated patients who were under follow up for at least 1 year.

\section{Exclusion criteria}

1. Patients of SUI who had been previously operated.

2. Patients who lost to follow up.

3. Patients who intended to further have children.

4. Incontinence due to bladder over activity.

All the female patients with complains of incontinence were evaluated. Patients having only SUI were further evaluated in detail including histories about previous surgeries, delivery, impact on quality of life, and severity of incontinence. Conservative management was first given to all the patients (behavioural therapy and PFMT). Total of 37 patients did not improved with conservative therapy and were taken for surgical correction.

TOT was done in 26, TVT in 3 and Bursch colposuspension in 8 patients. 3 patients lost to follow up (1 of TOT group and 2 of Bursch colposuspension surgery). Outcomes were compared from all the three patients in terms of correction of SUI, postoperative pain, hospital stay, need of redo surgery and complications such as wound infection, mesh erosion, and urinary retention.

\section{RESULTS}

Total 37 patients were enrolled in the study and 3 lost to follow up. Perurethral catheter was removed on next postoperative day in all the patients. All 8 patients of Bursch colposuspension voided without SUI. In TOT group, 22/26 voided without SUI after catheter removal, 3 underwent acute urinary retention and 1 patient had no improvement. 3 patients of retention were catheterized and trial voiding after 7 days was successful in all the patients. 3/26 patients of TOT had mesh erosion and infection; were managed by removal of mesh. There was no complication in TVT group. Outcomes regarding voiding function, incontinence and sexual satisfaction were measured at the end of 1,3, 6 and 12 months. All the three group of patients had comparable outcome.

\section{DISCUSSION}

Female stress urinary incontinence is defined as any involuntary leakage of urine during physical activity, sneezing, or coughing. It is diagnosed in more than 1 in 4 adult women and approximately half of all women suffering from urinary incontinence. Minassian et al (2003) found a wide range in the prevalence of incontinence with median prevalence as $27.6 \%$ (range: $4.8-58.4 \%{ }^{[11]}$. In a large pan European study by O'Donnell et al, it appeared that despite the bothersome nature of their symptoms and the obvious effect on quality of life, the majority of women did not seek medical intervention perhaps in the belief that treatment will not be successful or that surgery for their condition is perceived as unacceptable. SUI is often diagnosed by UDS. Blaivas suggested a classification of SUI depending on urethral mobility and intrinsic sphincter deficiency. Type 0 includes no leakage although vesical neck and proximal urethra open on stress, types 1 and 2 include urethral hypermobility, type 3 includes sphincter deficiency ${ }^{[12]}$.

Various surgeries for correction of SUI have evolved over the past several years. All corrective procedures aim for re-positioning the bladder neck and proximal urethra in a high intrapelvic position allowing equal pressure transmission to the bladder and proximal urethra, resulting in stress continence [13]. Retropubic suspension procedures are used mainly for the treatment of types 1 and 2 in the Blaivas classification (SUI secondary to urethral hypermobility). The most widely used technique is the Burch colposuspension ${ }^{[14]}$. Long-term follow up suggests a durable outcome with cure rates of $82 \%$ 
after 5 years and $69 \%$ after 12 years. Complications include wound problems, extended hospital stay, urinary retention, dysuria, de novo detrussor overactivity, urge incontinence, and recurrent UTI's. Sling surgery is considered the gold standard for the treatment of SUI as its placement is technically easy, with shorter operative time, less complications and high cure rates $(70 \%-90 \%)^{[15,16]}$. However, various studies have proved that no single best surgery exists. Many factors should be considered while choosing the appropriate operation for SUI in an individual patient for ensuring a favourable outcome or minimizing the risk of a poor outcome or associated complications. Sling and tape procedures are used mainly for type 1 and 3 SUI. Pubovaginal sling (PVS) is positioned at the bladder neck to provide urethral compression without obstruction during times of increased intra-abdominal pressure. Overall results are very good with success rate of over $80 \%{ }^{[17]}$. At present PVS is performed in patients with refractory SUI. Complications like urinary retention, detrussor overactivity, perforation and erosion have been reported.

In 1996, Ulmsten ${ }^{[18]}$ described a new minimal invasive technique, a tension-free vaginal tape (TVT) for urinary incontinence treatment. This technique soon became very popular because of its quite low complication rate, good results, and possibility to perform it in the outpatient department. TVT includes placement of polypropylene tape at the level of mid urethra and fixing the proximal ends in the rectus sheath through suprapubic stab incisions. TVT demonstrated a high success rate in various studies, identical to that of Burch colposuspension. It is also associated with short hospital stay and reduced risk of prolonged catheterization ${ }^{[19]}$. Complications such as bladder and bowel perforations and life threatening vascular injuries have been reported due to blind passage of the needles through the retropubic space ${ }^{[20,21]}$. Various reports showed success rate from $80 \%$ to $95 \%$ with a longer than 5-year follow-up.

The complications observed in TVT prompted the development of the Trans Obturator Taping (TOT) by Delorme in 2001 , to reduce retropubic route- associated complications

[22]

TOT involves placement of midurethral tape and anchoring it through the obturator foramen. Various studies have proved success rates of $80-90 \%$ [23,24]. Complications such as voiding dysfunction, blood loss and bladder perforation are far less than other procedures. TOT have been reported to be associated with prolonged pain referred to the groin and upper thigh, due to peripheral nerve injury and vaginal perforations due to a more horizontal trajectory of the needle passage ${ }^{[25]}$. Single vaginal incision slings requiring very limited intracorporeal dissection have been introduced which include TVT-Secur, Mini-Arc, Monarc, Ajust, Arcus-toArcus and Tissue Fixation Systems.

Before comparing and deciding on the most effective surgical intervention for stress urinary incontinence, a consensus is needed on how outcome should be defined. It has been suggested that surgical stabilisation at the level of the midurethra or bladder neck compensates for any loss of urethral support or function. The newer procedures attempt to support the urethra rather than attempt to fix it into an unnaturally high position ${ }^{[26]}$.

\section{CONCLUSION}

Patients with SUI should be explained all the surgical options and success and complications related to them. The pool of literature on SUI does not favour a surgical procedure in particular over the other as all the three procedures mentioned have comparable success rate and outcomes.

\section{REFERENCES}

1. Abrams P, Cardozo L, Fall M. The standardization of terminology of lower urinary tract function. Neurourol Urodyn. 2002;21:167. [PubMed: 11857671].

2. Abrams P, Artibani W, Cardozo L, et al. Clinical manual of incontinence in women, 21st ed., Paris, France: Health Publisher Ltd.; 2005.

3. Nygaard I, Girts T, Fultz N, Kinchen K, Pohl G, Sternfeld B: Is urinary incontinence 
a barrier to exercise in women? Obstet Gynecol 2005, 106:307-314.

4. Papanicolaou S, Hunskaar S, Lose G, Sykes D: Assessment of bothersomeness and impact on quality of life of urinary incontinence in women in France, Germany, Spain, and the UK. BJU Int 2005, 96:831838.

5. Oh SJ, Ku J, Choo MS, Yun J, Kim D, Park WH: Health-related quality of life and sexual function in women with stress urinary incontinence and overactive bladder. Int $\mathbf{J}$ Urol 2008, 15:62-67.

6. Mostafa A, Agur W, Abdel-All M, et al. A multicentre prospective randomised study of single-incision mini-sling (Ajust(®)) versus tension-free vaginal tape-obturator (TVT$\mathrm{O}^{\mathrm{TM}}$ ) in the management of female stress urinary incontinence: pain profile and shortterm outcomes. Eur J Obstet Gynecol Reprod Biol. 2012. [Epub ahead of print].

7. Ulmsten U, Henriksson L, Johnson P, et al. An ambulatory surgical procedure under local anesthesia for treatment of female urinary incontinence. International Urogynecology Journal and Pelvic Floor Dysfunction. 1996;7:81-85. discussion 85-86.

8. Delorme E. Transobturator urethral suspension: mini-invasive procedure in the treatment of stress urinary incontinence in women. Progres en Urologie. 2001;11:13061313.

9. De Leval J. Novel surgical technique for the treatment of female stress urinary incontinence: transobturator vaginal tape insideout. European Urology. 2003;44:724-730.

10. Jacklin P, Duckett J, Renganathan A. Analytic model comparing the cost utility of TVT versus duloxetine in women with urinary stress incontinence. Interna-tional Urogynecology Journal. 2010;21:977-984.

11. Minassian VA, Drutz HP, AlBadr A. Urinary incontinence as a worldwide problem. Int $\mathrm{J}$ Gynaecol Obstet. 2003;82:327-38. [PubMed: 14499979].
12. Blaivas JG. Classification of stress urinary incontinence. Neurourol Urodyn. 1984;2:103.

13. Enhorning G. Simultaneous recording of the intravesical and intraurethral pressure. Acta Obstet Gynecol Scand 1961;276s:1-69.

14. Ward K, Hilton P. Prospective multicentre randomised trial of tensionfree vaginal tape and colposuspension as primary treatment for stress incontinence. BMJ. 2002;325:6770.[PMCID: PMC117136] [PubMed: 12114234].

15. Jain P, Jirschele K, Botros SM, Latthe PM. Effectiveness of midurethral slings in mixed urinary incontinence: a systematic review and meta-analysis. Int Urogynecol $\mathbf{J}$ 2011;22:923e32.

16. Bidmead J, Cardozo L. Sling techniques in the treatment of genuine stress incontinence. BJOG 2000;107:147e56.

17. Jarvis GJ. Surgery for genuine stress incontinence. $\mathrm{Br} \mathrm{J}$ Obstet Gynaecol. 1994;101:371-4. [PubMed: 8018606].

18. Ulmsten U, Petros P. Intravaginal slingplasty (IVS): an ambulatory surgical procedure for treatment of female urinary incontinence. Scand J Urol Nephrol. 1995;29:75-82.

19. Ward KL, Hilton $P$ for the UK \& Ireland TVT Trial Group. Tension- free vaginal tape versus colposuspension for primary urodynamic stress incontinence: 5-year follow up. BJOG. 2008;115:226-233.

20. Deng DY, Rutman M, Raz S, et al. Pre $\neg$ sentation and management of major complications of midurethral slings: are complications under-reported? Neurourol Urodyn. 2007;26:46-52.

21. Novara G, Artibani W, Barber MD, et al. Updated systematic review and metaanalysis of the comparative data on colposuspensions, pubovaginal slings, and midurethral tapes in the surgical treatment of female stress urinary inconti-nence. European Urology. 2010;58:218-38. 
22. Delorme E, Droupy S, De Tayrac R, et al. Transobturator tape Uratape): a new minimally-invasive procedure to treat female urinary incontinence. Eur Urol. 2004;45:203-207.

23. Harding C, Horsburgh B, Page T, Thorpe AC. A prospective study of surgeon and patient perceived outcome following transobturator tape insertion for treatment of urodynamic stress incontinence. BJMSU. 2009;2:197-201

24. Roumeguere T, Quackels T, Bollens R, de Groote A, Zlotta A, Bossche MV, et al. Trans Obturator Vaginal Tape (TOT) for female incontinence: One year follow up in 120 patients. Eur Urol. 2005;48:805-9. [PubMed: 16182440].

25. Richter HE, Albo ME, Zyczynski HM, et al. Retropubic versus transobturator mi durethral slings for stress incontinence. N Engl J Med. 2010;362(22):2066-76.

26. Plzak 3rd L, Staskin D. Genuine stress incontinence theories of etiology and surgical correction. Urol Clin North Am 2002;29(3): 527-35. 